\title{
Perspective and Experience of Operating Room Personnel on Ethical Behaviors
}

\author{
Soheila Bakhtiari ${ }^{1,2}$, Mahnaz Rakhshan ${ }^{3}$, Mohsen Shahriari ${ }^{4}$, Farkhondeh Sharif ${ }^{5^{\star}}$
}

${ }^{1}$ Ph.D candidate of Nursing, Student Research Committee, Shiraz University of Medical Sciences, Shiraz, IRAN

${ }^{2}$ Department of Operating Room, School of Nursing and Midwifery, Nursing and Midwifery Care Research Center, Isfahan University of Medical Sciences, Isfahan, IRAN ${ }^{3}$ Associate professor, Community Based Psychiatric Care Research Center. School of Nursing and Midwifery, Shiraz University of Medical Sciences, Shiraz, IRAN

${ }^{4}$ Associate Professor of Nursing, Department of Adult Health Nursing, School of Nursing and Midwifery, Nursing and Midwifery Care Research Center, Isfahan University of Medical Sciences, Isfahan, IRAN

${ }^{5}$ Professor, Community Based Psychiatric Care Research Center. School of Nursing and Midwifery, Shiraz University of Medical Sciences, Shiraz, IRAN

*Corresponding Author: fsharif2008@gmail.com

Citation: Bakhtiari S, Rakhshan M, Shahriari M, Sharif F. Perspective and Experience of Operating Room Personnel on Ethical Behaviors. Electron J Gen Med. 2020;17(3):em198. https://doi.org/10.29333/ejgm/7821

ARTICLE INFO

Received: 30 Aug. 2019

Accepted: 6 Feb. 2020

\section{ABSTRACT}

Background: unethical behaviors necessitate a specific focus on ethical behavior. A better understanding of the concept can be obtained through the perspective and experience of surgical teams on ethical behavior. As a direct result, the knowledge and performance of the nurses as well as the patients' satisfaction can be elevated.

Objectives: The present study aimed to assess ethical behavior based on the perspective and experience of the OR personnel.

Research Design: A qualitative study to identify the perspective and experience of OR personnel on ethical behavior, using the conventional qualitative content analysis method.

Participants and Research Context: OR personnel at educational hospitals affiliated to Isfahan University of Medical Sciences were selected from April 2017 to June 2018 Using a purposive sampling method (n=26).In-depth semi-structured interviews Were Used For Data Collection.

Ethical Considerations: The study was approved by University's Ethics Committee. Prior to the interviews, the research goals and method were explained, the confidentiality of any disclosed information was guaranteed, and voluntary participation was emphasized.

Findings: Based on the interview data, four themes were extracted, namely "Enhance professional commitment", "Strive for excellence", "Respect for human dignity", and "Enhance safety".

Discussion and Conclusion: The findings highlighted the provision of compassionate care by the OR personnel, in accordance with scientific standards. Fair job division and non-discriminatory behavior between the members of the OR team were emphasized. Our findings emphasized the importance of psychological and physical safety. Personal and professional excellence can be achieved through conscious actions by the personnel to correct their shortcomings, improvement of the capabilities of colleagues, and effective teamwork. The findings enlighten healthcare personnel and managers on the concept of ethical behavior toward designing better policies and plans for patient care. the nursing profession will be respected more and ethical behavior and professionalism will become widespread.

Keywords: ethical behavior, operating room, nursing, qualitative research, content analysis, nurses

\section{INTRODUCTION}

From a psychological point of view, behavior is influenced by an interplay between personality traits and the physical and social conditions of an environment (1). Some psychologists emphasized on the prominent role of the environmental factors whereby an individual and its environment influence each other. These factors are believed to be involved in the development of human behavior (2). Considering all environmental factors (natural conditions and sociocultural factors) affecting human behavior, it is logical to deduce that peoples' behavior differs in different environments, cultures, and social conditions (3). In this context, ethics are a platform upon which behavioral standards are defined as a framework for personal conduct and practices (4). Ethical behavior is a complex concept; it defines the social structure between people living and working together whereby their functioning influence each other (5). Therefore, there is no single variable that can comprehensively demonstrate the psychology of ethical behavior (6).

Considering recent advancements in healthcare services and related technologies, it is important to be observant of ethical behavior by nurses and to address the growing concern about unethical behaviors and their underlying factors $(7,8)$. Although nurses are fully aware of nursing ethics, the main concern is whether they are actually in the position to practice ethical behavior in clinical settings (9). As a direct result, ethical 
behavior has become a research priority since it is a critical element of nursing care and adherence to ethical behavior is an essential part of the nursing profession $(10,11)$.

Nowadays, unethical behavior in healthcare has become a serious challenge to healthcare providers, national economies, and society $(12,13)$. Several studies have reported on the occurrence of unethical behavior in healthcare, particularly in the hospital operating room (OR) (14-17). However, only a few studies have comprehensively addressed the concept of ethical behavior based on the perspective and experience of the OR personnel. Some studies have mainly addressed the concept of ethical behavior from the viewpoint of organizational management or from the psychological perspective. Unfortunately, the majority of the studies on the nursing profession have approached ethical behavior based on certain presumptions without considering its full range of dimensions. Some studies have assessed ethical behavior based on moral reasoning to determine right from wrong (18), while ethical behavior involves making conscious decisions and acting accordingly $(19,20)$. Other studies have conditioned ethical behavior to ethical decision-making, while several studies have shown a clear distinction between ideal decisionmaking and realistic moral behavior (21).

The display of ethical behaviors strongly depends on the context-specific setting in which nursing care is provided; however, most theoretical frameworks have not considered this parameter (22). For instance, hospital ORs are secluded, cannot be monitored directly, the patient is unconscious, and individuals with diverse specialties are present. Such a contextspecific setting is more prone to the emergence of unethical behavior compared to other hospital sections. Clearly, exposure of the surgical team members to a high level of stress (23-26) may cause behavioral changes to the extent that some may even opt to change jobs (27). Previous studies have reported that burnout syndrome, common among OR personnel, is the result of working in stressful settings which in turn can cause anti-social behavior (28-30). In addition, ethical distress among nurses is indicative of their inability to work in accordance with their code of ethics (31-35).

A detailed and comprehensive assessment of the experience of OR personnel allows identification of their perception of ethical behavior. Considering the fact that moral principles are deep-rooted in the Iranian culture and religion, it is expected that people conduct their job responsibilities in a moral and humane way and in accordance with the Islamic teachings (36). Contrary to these expectations, several studies have reported unethical behavior by healthcare providers in Iran (37-41). As a direct result, the present qualitative study aimed to assess various aspects of ethical behavior among one of the most challenged groups of healthcare providers, namely the OR personnel.

\section{METHODS}

\section{Study Design}

As part of a larger research project, the present qualitative study aimed to identify the perspective and experience of OR personnel on ethical behavior using the conventional qualitative content analysis method.

\section{Participants and Setting}

The present qualitative study was conducted from April 2017 to June 2018 at educational hospitals affiliated to Isfahan University of Medical Sciences, Isfahan, Iran. The target population was the surgical team at various educational hospitals. The purposive sampling method was used to recruit participants and the sampling was continued until data saturation (i.e., the emergence of no new category with substantive characteristics or dimension). The inclusion criteria were a minimum of 6 -month work experience, holding at least a bachelor's degree, mental and psychological ability to participate in an interview, and willingness to participate. An effort was made to select participants with maximum diversity in terms of age, sex, and work experience. Initially, 14 OR nurses and technicians, involved with elective and emergency surgeries, were recruited. In order to obtain richer information, additional participants with other expertise were enrolled, namely surgeons $(n=2)$, anesthesiologists $(n=2)$, and clinical educators $(n=4)$. In addition, four Nursing Manager were recruited to obtain complementary information. The demographic characteristics of the 26 participants are described in Table 1.

\section{Data Collection}

The experience and perspective of the participants were assessed through 31 in-depth semi-structured interviews. Subsequent to the first round of interviews, to clarify ambiguities and obtain complementary information, six additional repetitive interviews were held with two nursing managers and one clinical educator. Note that from the initial 26 interviews, the first interview with one OR technician was discarded since the given information was too scattered despite spending more than 2 hours to probe for comprehensive information. The face-to-face interviews were conducted by the first author at a location of the participants' choice and each interview lasted approximately 55 minutes. Prior to the interviews, all participants were informed about the research goals and procedures. In addition, the confidentiality of any disclosed information was guaranteed. Written informed consent was obtained from all the participants.

The interviews started with open questions, such as "What is your understanding of ethical behavior in the OR?" Then, to probe for more information and clarifications, questions such as "What are your practical experiences with ethical behavior in the OR?", "What do you consider ethical in the OR?", and "Please elaborate further" were asked. With the permission of the participants, an audio recording of the interviews was made and transcribed verbatim using Microsoft Word 2013. Additionally, in support of data analysis, at different intervals (morning and afternoon shifts) as well as pre- and post-surgery, field notes were made on the attitude of the OR personnel toward the patients and the surgical team.

\section{Data Analysis}

The data were analyzed using the qualitative content analysis method in accordance with the concept described by Lundman and Graneheim. At the end of each interview, the audio recording together with the field notes was meticulously transcribed. Following multiple reviews of the transcription, initial semantic units (codes) were identified. The extracted codes were then classified in terms of similarities and differences based on which the categories were defined. The 
Table 1. Demographic and clinical characteristics of the participants

\begin{tabular}{|c|c|c|c|c|c|}
\hline participant & Educational level & Age(years) & Gender & Position & Working years \\
\hline $\mathrm{P} 1$ & Bachelor & 39 & Mile & OR Nurse & 20 \\
\hline $\mathrm{P} 2$ & Bachelor & 27 & Female & OR Nurse & 4 \\
\hline P3 & Bachelor & 29 & Male & OR Nurse & 5 \\
\hline $\mathrm{P} 4$ & Bachelor & 41 & Female & OR Nurse & 21 \\
\hline P5 & Bachelor & 26 & Female & OR Nurse & 4 \\
\hline P6 & Bachelor & 49 & Male & Nursing Manager & 26 \\
\hline P7 & Bachelor & 44 & Female & OR Nurse & 23 \\
\hline P8 & Bachelor & 46 & Male & Nursing Manager & 24 \\
\hline P9 & Bachelor & 26 & Female & OR Nurse & 5 \\
\hline $\mathrm{P} 10$ & Bachelor & 36 & Female & OR Nurse & 16 \\
\hline P11 & Bachelor & 39 & Female & Nursing Manager & 17 \\
\hline $\mathrm{P} 12$ & MSc. & 28 & Female & Clinical Educator & 3 \\
\hline P13 & Bachelor & 51 & Female & Nursing Manager & 25 \\
\hline P14 & MSc. & 31 & Female & Clinical Educator & 16 \\
\hline $\mathrm{P} 15$ & Bachelor & 40 & Female & OR Nurse & 17 \\
\hline P16 & Bachelor & 49 & Female & Anesthesia Personnel & 25 \\
\hline P17 & $\mathrm{PhD}$ & 53 & Female & Clinical Educator & 25 \\
\hline P18 & Bachelor & 51 & Female & OR Nurse & 25 \\
\hline P19 & $\mathrm{PhD}$ & 44 & Male & Anesthesiologist & 16 \\
\hline $\mathrm{P} 20$ & Bachelor & 49 & Male & OR Nurse & 25 \\
\hline $\mathrm{P} 21$ & Bachelor & 43 & Female & OR Nurse & 21 \\
\hline $\mathrm{P} 22$ & Bachelor & 49 & Female & OR Nurse & 24 \\
\hline $\mathrm{P} 23$ & PhD & 50 & Male & Surgeon & 14 \\
\hline P24 & Bachelor & 47 & Male & OR Nurse & 24 \\
\hline $\mathrm{P} 25$ & $\mathrm{PhD}$ & 48 & Female & Surgeon & 22 \\
\hline $\mathrm{P} 26$ & MSc. & 28 & Female & Clinical Educator & 13 \\
\hline
\end{tabular}

categories were then reviewed, compared, and grouped to determine the main themes. Data analysis was performed using the MAXQDA 10 software.

\section{Rigor}

Triangulation of data sources was done based on the importance of variation in time, space, and person during observations and interviews. Observations on the nurses, technicians, clinical educators, nursing managers, surgeons, anesthesiologists, and patients were made at different intervals (morning and afternoon shifts) and in different ORs. To confirm the degree of data convergence, a sample of the interview transcriptions and extracted codes were presented to the participants and reviewed jointly with the research team. To achieve proportionality, a sampling technique with a maximum variation (age, sex, and work experience) was used. To fulfill the transferability criterion, a full description of the results, the data analysis, and quotations of the participants' statements were provided. The credibility and dependability criteria were confirmed through extensive teamwork among the research team combined with interaction and supervision by experts.

\section{Ethical Considerations}

The present study was approved by the Ethics Committee of Shiraz University of Medical Sciences, Shiraz, Iran (code: IR.SUMS.REC.1396.S600). The interviews were held at the preferred location by the participants. Prior to the interviews, the research goals and method were explained, the confidentiality of any disclosed information was guaranteed, and voluntary participation was emphasized. Written informed consent was obtained from all the participants.

\section{RESULTS}

A total of 26 individuals participated in the study. The participants were OR nurses $(n=14)$, surgeons $(n=2)$, anesthesiologists $(n=2)$, nursing managers $(n=4)$, clinical educators $(n=4)$. The demographic characteristics of the participants are outlined in Table 1.

Analysis of the interview data resulted in 1,523 primary codes from which 13 categories and 4 themes were extracted (Table 2). The main themes were "Enhance professional commitment", "Strive for excellence", "Respect for human dignity", and "Enhance safety".

\section{Enhance Professional Commitment}

The theme "Enhance professional commitment" included three categories, namely "Improve clinical skills", "Accountability", and "Adherence to Job discipline."

The participants believed that personnel who improved their clinical skills had a higher level of professional commitment. A participant stated: "The OR personnel should improve their work-related skills in order to execute tasks in accordance with the fundamentals of medical science." (P5)

The importance of accountability was emphasized by several participants. A participant stated: "Upon entry to the OR, each member of the surgical team must feel responsible for both the patient and other team members. They should feel responsible and held accountable for their actions and must always remind themselves to hold onto this virtue." (P9)

The participants believed that those who respected the rules and regulations and adhered to discipline at work had a higher level of professional commitment. A participant stated: "Just like on a military base, the OR personnel must follow a strict discipline and order. The OR is not a place for trial and error; those who are committed to their profession fully understand what I mean." (P1) 
Table 2. Extracted themes and categories from the interview data

\begin{tabular}{|c|c|c|}
\hline \multirow{14}{*}{$\begin{array}{c}\text { Ethical } \\
\text { behavior }\end{array}$} & Themes & Categories \\
\hline & \multirow{3}{*}{ Enhance professional commitment } & Improve clinical skills \\
\hline & & Accountability \\
\hline & & Adherence to Job discipline \\
\hline & \multirow{4}{*}{ Strive for excellence } & Improve character traits \\
\hline & & Strive for the growth and development of the surgical team \\
\hline & & Enhance the knowledge of patients and family caregivers \\
\hline & & Efforts to enhance teamwork \\
\hline & \multirow{3}{*}{ Respect for human dignity } & Effective interactions \\
\hline & & Respect for personal identity of others \\
\hline & & Fairness \\
\hline & \multirow{3}{*}{ Commitment to Enhance safety } & Avoid abuse \\
\hline & & Create a calm atmosphere \\
\hline & & Commitment to protection and prevention \\
\hline
\end{tabular}

\section{Strive for Excellence}

The categories identified under this theme were "Improve character traits", "Strive for the growth and development of the surgical team", "Enhance the knowledge of patients and family caregivers", and "Efforts to enhance teamwork."

The participants mentioned that those who pro-actively aimed for the growth and development of themselves and other team members contributed to the enhancement of ethical behavior. They believed that professional excellence also encompassed improving character traits such as generosity, humbleness, dedication, self-reliance, and being determined. A participant stated: "We can be more effective in our job if we improve certain character traits. I do not only mean accomplishments at work, but to become a righteous person is also a major achievement." (P21)

The participants expressed the importance of contributing to the growth and development of colleagues, patients, and family caregivers. They emphasized on both knowledge transfer as well as ethical teachings to colleagues, and the provision of medical information and training to the patients and their family caregivers.

The majority of the participants considered efforts to enhance teamwork as an important element of striving for personal and organizational excellence. A clinical educator stated: "OR activities are a good example of efficient teamwork. The surgical team does its utmost during surgery to ensure the best possible outcome such that the patient can be transferred to the recovery room without any complications. Each member of the surgical team should perform exceptionally well to ensure a successful surgery." (P17)

\section{Respect for Human Dignity}

The theme "Respect for human dignity" included three categories, namely "Effective interactions", "Respect for the personal identity of others", and "Fairness". The result of the interview data indicated that those who had more respect for human dignity made a higher contribution to effective interactions. In this regard, the participants expressed the importance of effective interaction and communication. A participant stated: "Effective interaction between the surgical team (surgeon, anesthesiologist, nurses, and technicians) is essential as we work together toward the same goal. In addition, effective communication creates a collective sense of respect." (P9)

The participants believed that respect for one's personal dignity (culture, autonomy, and physical space) was indicative of the respect for the personal dignity of patients, their family caregivers, and for the surgical team. A participant stated: "One needs to respect a patient as an individual irrespective of his/her social status or background. Such an attitude should also extend to their family caregivers as well as the surgical team." (P3)

Fairness toward patients, family caregivers, and the surgical team was also perceived as an element of respect for human dignity. A participant stated: "Duties of certain members of the surgical team should be assigned justly and include the element of job rotation. It is not fair that one is always a scrub nurse or a circulating nurse. At times a scrub nurse must remain active and on her feet for long hours, while a circulating nurse remains seated during the operation." (P15)

\section{Commitment to Enhance safety}

The categories associated with the theme Commitment to Enhance safety were "Avoid abuse", "Create a calm atmosphere", and "Commitment to protection and prevention". Safety enhancement, which includes both the physical and psychological safety in the OR, was viewed as the surgical team's main goal. An OR nurse stated: "Even after successful surgery, an anesthetized patient should not be rolled over or moved aggressively to prevent possible physical injuries. One needs to care for patient safety before, during, and after surgery." (P7)

A calm atmosphere without any stress was regarded as a contributing factor to psychological safety. An OR technician stated: "In particular, it is essential to maintain a calm atmosphere without any stress prior to surgery. The surgical team needs calm conditions, otherwise, not only the performance of the whole team will be negatively affected, but it may also cause harm to the patient." (P22)

Based on the experience of the participants, the lack of safety was the main cause of physical injuries to both the patients and the personnel in the OR. In this regard, providing preventive and protective measures to protect the patients and the surgical team are of paramount importance.

\section{DISCUSSION}

The present qualitative study aimed to establish how ethical behavior manifests itself, based on the perspective and experience of OR personnel. Analysis of the interview data resulted in four themes, namely "Enhance professional commitment", "Strive for excellence", "Respect for human dignity", and "Commitment to Enhance safety". Based on the theory of virtue ethics, a study (42) outlined a model for nursing 
ethical behavior which included three areas of ethical behavior toward patients, family caregivers, and the treatment team.

The majority of the participants viewed professional commitment as the hallmark of ethical behavior. The categories associated with this theme were "Improve clinical skills", "Accountability", and "Adherence to Job discipline". The pivotal role of professional commitment has been stated by several nursing professionals as it empowers nurses to perform their tasks (43). A previous study concluded that nurses perceive professional commitment as an inner force that encourages their selflessness, inspires them to provide care with kindness, and to view the job as a spiritual responsibility (44). Some studies have identified professional commitment as the main factor that influenced the employee's decision not to leave the profession (45-47). Nurses in particular face the dilemma of continuing their career as they are confronted with several new challenges, such as a higher level of complexity in nursing care, the increasing use of advanced technologies in providing health care, heavy reliance on other team members, increased competition, and budget limitation (48). This dilemma is more prominent in the OR, as the most important section in any treatment center, since it is vital to retain experienced and capable employees. Based on our findings, we believe that management teams can empower hospital personnel by developing systematic plans to enhance their clinical competence by introducing suitable motivation programs.

Enhancement of professional commitment is a process that involves continuous effort. The participants were of the opinion that improving clinical skills is an element of the process of enhancing professional commitment, and subsequently has a positive effect on ethical behaviors. A previous study identified clinical competence as a category of professionalism (49). However, there are concerns over the lack of utilization of certain clinical skills, particularly with regard to the quality of nursing education and training programs (50). The findings of the present study highlighted that clinical skills should also encompass the provision of care in accordance with scientific standards, time management in clinical practice, and the promotion of theoretical knowledge and practical competencies. The majority of the participants considered the provision of care in accordance with scientific standards as a dimension of improving clinical skills, which consequently enhanced their professional commitment.

Accountability was another category of enhancing professional commitment. However, in a previous study based on the theory of virtue ethics, this category was not identified (43). This finding signifies the importance of accountability of the OR personnel from the perspective of the participants in the current study. Nursing professionals have indicated that nurses should be held accountable for the decisions they make and their subsequent outcomes (44). Other studies concluded that accountability, along with other factors (consistency of care, accurate task performance, and self-confidence), is indicative of competent care and increases commitment and the sense of responsibility and the will to make an extra effort to promote professional values $(51,52)$.

Strive for excellence was another theme associated with the ethical behavior of OR personnel. This theme included the categories of "Improve character traits", "Strive for the growth and development of the surgical team", "Enhance the knowledge of patients and family caregivers", and "Efforts to enhance teamwork". Moulana, the foremost Iranian theologist and philosopher, described ethical behavior as a form of personal conduct; starting with a willful and conscious act against the boundaries of the personal universe and evolving into a continuous effort to overcome the constraints to expand the personal universe (53), which could be viewed as striving for excellence. Farabi, another famous Iranian philosopher, considered a combination of theory and practice as the prerequisite to achieve excellence. He believed that humans will achieve excellence if they remain firm in good and worthy conduct and try to continue with the good deed and behavior (54).

Based on the results, we found that character traits such as generosity, humbleness, dedication, self-reliance, and being resolute were complementary characteristics in the OR. Such traits cannot be achieved easily and require going through a challenging path, spending time, study, thought, contemplation, and re-evaluation; rewarded with achieving personal and professional excellence. Farabi believed that a perfect human is one who has achieved virtue, completed theoretical knowledge, achieved the nobility of ethics in practice, and has reached fullness in ethical behavior (54). A previous study reported that nurses perceived that the belief in divine rewards made their work enjoyable, moral (a sense of being a savior, spirited and passionate about the job), and gave them a sense of excellence (55). Some other studies have indicated that by implementing certain management skills, character traits are improved which in turn encourages and motivates the personnel to perform tasks beyond the predefined job description and ultimately elevates the efficiency of the organization $(56,57)$.

The results of the present study identified "Efforts to enhance the growth and development of the surgical team" and "Improve the knowledge of the patients and family caregivers" as the categories of striving for excellence. The subcategories associated with "Efforts to enhance the growth and development of the surgical team" were identified as "Teaching of ethical practice to the surgical team" and "Knowledge transfer to the surgical team". The sub-categories associated with "Improve the knowledge of the patients and family caregivers" were identified as "Offering information and training to the patients" and "Offering information and training to the family caregivers."

The participants viewed that the transfer of knowledge and the teaching of ethics to their colleagues, in particular to junior counterparts, play a pivotal role in developing the next generation of competent professionals, which in turn elevates performance levels and the sustainability of treatment centers. A previous study concluded that knowledge transfer by nurses to their colleagues indicates the presence of optimal leadership skills (58). Unfortunately, the provision of medical information to patients and their family caregivers is often neglected by the OR personnel, although it is a part of the Iranian patient's rights charter (59). We believe that by giving adequate information and guidance to the patients and their family caregivers, they gain hope and the obtained knowledge will generate a positive mindset. In addition, their families and the community become aware of the nurses' ethical behavior and ultimately promotes the stature of the nursing profession in society as a whole.

Efforts to enhance teamwork was also identified as a category of striving for excellence. We found that exceptional teamwork among OR personnel is essential. Note that the OR personnel comprise of different people with different 
expertise; in an environment that can be stressful and intense. Therefore, comprehensive teamwork planning is required to reduce potential mistakes and improve patient safety (60). We found that the elements involved in successful teamwork included collaboration and interaction with other team members, monitoring the performance of colleagues, peer-topeer knowledge exchange, and aiming to teach and learn from colleagues before, during, and after surgery. Considering the fact that training is the most common methods for improving teamwork (61), a comprehensive training program for OR personnel is recommended.

The theme "respect for human dignity" included the categories "Effective interactions", "Respect for the personal identity of others", and "Fairness". Respect for patients' dignity is an essential part of nursing care (62). A previous study identified three key concepts that required an ethical attitude to nursing, namely care, human dignity, and vulnerability of people (63). In another study, maintaining patient's dignity was identified through five themes; respect, protection of privacy, emotional support, maintaining body image, and equal treatment for all patients (64). Whereas, in the present study, respect for the personal identity of others (patients, family caregivers, and surgical team) was identified as one of the main categories of the theme "Respect for human dignity". The subcategories of "Respect for the personal identity of others" were protecting privacy, autonomy, and accepting cultural backgrounds; indicating the importance of acknowledging the concept of identity from the perspective of the OR personnel. Among all sociological standpoints, the symbolic reciprocal theory has extensively addressed the term identity. Based on this viewpoint, meanings (in general) and identity (in particular) form the process of interaction between people (65). From this perspective, the type and quality of interpersonal relationships between the OR personnel and patients, as well as the surgical team, is of great importance as it affects their identity.

Protecting privacy is an innate quality of a person and privacy is a basic human right (66-68). The Iranian patient's rights charter defined five key items and 37 sub-items, among which is the respect for patients' physical space (59). Nonetheless, there are reports of violation of patients' privacy and disregard of their requests (37). The finding of the present study indicated that patients, as they are unconscious during surgery, entrust themselves to the hands of the OR personnel to protect their privacy. Therefore, it is essential that OR personnel take this matter seriously since it causes a lot of preoperative stress to patients (69). For instance, the stress was to the extent that a female patient in our study insisted that her body should be fully covered after anesthesia.

Patients' autonomy was also associated with respect for personal identity. The participants in our study indicated the importance of being able to express their views on the treatment method, following clarifications by the treatment team. However, in line with our findings, a previous study also reported that patients were not generally asked about their preferred method of anesthesia $(70,71)$. Respect for the cultural background of patients, as well as colleagues, was an element of respect for personal identity. A previous study reported that respect for religious, national, and ethnic beliefs of patients is recognized by both the patients and the treatment team as part of patients' rights (72).

Effective interaction with patients, family caregivers, and the surgical team requires a specific focus from the OR team.
Several nursing theorists (e.g., Hildegard Pepla, Ida Jean Orlando, and Paterson-Zderad) have considered communication as the main pillar of the nursing profession and emphasized on bilateral interaction between the patient and the treatment team (73). Another nursing theorist, Patricia Benner, described the nursing profession as a caring relationship (74). Due to the inherent stressful conditions in the OR, exacerbated by complex instruments, effective communication between the patient and the surgical team is required in such environment more than any other section of the hospital (75). However, it has been reported that verbal communication with patients was missing in the care provided by OR staff (76). In a previous study, sympathy was identified as a sub-category of emotional support (51), while we identified such parameters (e.g., sympathy, confidence building, and verbal/non-verbal communication) as sub-categories of effective interaction. This indicated that the OR personnel considered effective interaction as an important concept and felt that both communication and sympathy are necessary, despite the limited time they have for a patient. They described sympathy as a friendly relationship, the ability to listen and show understanding, and to take the underlying cause for certain behavior into consideration. The participants stated that confidence building can be achieved through reassurance, honesty, and cordiality. They emphasized that having a sense of humor is a prerequisite to facilitate effective communication and manage the tense conditions in the OR.

Dignity is one of the most important aspects of human rights (77), which includes respect for the dignity of patients as well as of healthcare providers. The results of the present study showed that respect for dignity among the surgical team is an essential part of ethical behavior in the OR. In this regard, the participants emphasized on effective communication as an illustration of respect for their colleagues. Because of the fact that a surgical team includes people with diverse expertise, it is a major challenge to establish effective communication and harmony among the team members (78); probably due to the lack of interaction and communication training (79). Therefore, it is recommended to plan and execute specific interprofessional education programs to promote effective interaction between the OR personnel.

Fairness was another category associated with respect for dignity, which included non-discrimination in patient care, fair distribution of tasks among colleagues, and nondiscrimination in the communication among members of the surgical team. In a previous study, fairness was identified as a sub-category of ethical behavior toward patients and their family caregivers (43). Whereas in the present study, fairness was identified as one of the main categories of respect for human dignity; indicating the importance of fairness among the OR personnel. As experienced by some participants, contrary to the code of ethics, the members of the OR personnel behave more politely and provide better care to patients with a higher social status. Moreover, they seemed to show more respect and flexibility toward surgeons compared to their direct colleagues, even to the extent that they blindly followed the surgeon's instructions at the risk of harming the patient. Therefore, it is vital to avoid such unethical behaviors to prevent discrimination and harm to patients. Another example of unethical behavior, as stated by a participant, was related to the division of tasks between the scrub and circulating nurses, whereby the scrub nurse had a higher workload. Since these nurses can divide the tasks themselves, 
they should consider the fair allocation of the workload to avoid unethical behavior.

The results of the interview data showed that Commitment to Enhance safety in the OR was considered as an important domain of ethical behavior. This theme included three categories, namely "Avoid abuse", "Create a calm atmosphere", and "Commitment to protection and prevention". The majority of studies on safety have only addressed its physical aspect, whereas we additionally emphasized on the psychological safety. This was mainly due to the specific conditions in the OR, the patients, and the type of professional and personal relationships that exist among the members of the surgical team. Based on the experience of the participants, there were cases of verbal, non-verbal, and physical abuse not only against the patients and their family caregivers but also against individual members of the surgical team. They considered any form of abuse, in particular against patients, unethical and to be avoided regardless of the situation. A previous study suggested that certain actions, which could be interpreted as inhumane, are taken to exert firmness in order to manage a tense condition in the OR (80). Nonetheless, from the professional and ethical point of view, nurses are obliged to defend abused patients.

The majority of the participants emphasized on the importance of a calm atmosphere in the OR. However, they expressed the lack of verbal communication by the surgical team with the patients and their family caregivers. This is despite the fact that such communications combined with compassion, kindness, confidence building, and giving hope and peace of mind would ultimately calm the patients and their family caregivers. A previous study highlighted the importance of retaining patients' calm and comfort, particularly in children, throughout the surgery process; from the entry of the patient in the OR to the initiation of anesthesia, the surgery itself, and beyond (81). The findings of the present study indicated that the scrub and circulating nurses can greatly contribute to the creation of a calm atmosphere and managing of the tense environment. Particularly at sensitive and complex surgeries, they should keep their calmness, take timely and accurate actions, and reassure others. Moreover, relaxing music in the operating room is a quick win in calming both the patients and the surgical team.

The majority of the participants raised their concern about the high rate of potential harm to patients during surgery. Since patients are unconscious during surgery, prevention of harm to patient lies entirely with the OR personnel. The circulating nurse should be watchful of the patients' condition, identify potential dangers, and take immediate action (e.g., patient falls off an operating bed while under anesthesia). Furthermore, the use of mobile phones should be prohibited in the OR room.

One of the main priorities of the healthcare system, particularly in the OR, is an improved level of treatment and care and patients' safety (82). The participants of the present study emphasized on compliance with the principles of infection control and blamed inadequacy of equipment and tools as the main reason for lack of sterility in the OR. A previous study suggested that hospitals with adequate instrumentation have a better track record of disinfection and sterilization, and consequently are better equipped to safeguard patients' safety $(83,84)$. Our participants expressed their concern about defect instruments and recommended the use of smart systems to measure temperature and humidity and to monitor the level of microbial contamination, dust, and noise.

In line with our findings, a previous study concluded that deployment of suitable equipment and a sufficient number of competent nurses are essential to improve patients' safety (85). Another concern of the participants, associated with safety in the OR, was occupational hazards. It has been reported that $80 \%$ of the needle stick injuries occur in the OR (23). The participants specifically mentioned hazards such as the use of flammable materials, ionizing radiation, gases, and chemical materials as well as lack of protective equipment such as surgical face shields and leaded aprons.

Job burnout is especially common among OR personnel and was a concern among our participants; requiring the special attention of hospital managers. Dedicated programs such as refresh workout and fitness training as well as educational courses could improve the performance and job satisfaction of the personnel. We also noted the importance of the proper management of medical errors that occurs in the OR. It is essential that OR personnel acknowledge the error and seek guidance from competent and experienced colleagues; a teamwork approach to reduce the impact of an error. It has been reported that there was a significant correlation between teamwork among nurses and patient safety (86).

Overall, the findings of the present study highlighted the provision of compassionate care by the OR personnel, in accordance with scientific standards. Furthermore, protection of patients' privacy, constructive and professional interaction with the surgical team, fair job division between the scrub and circulating nurses, and non-discriminatory behavior between the members of the OR team were also underlined. Commitment to promoting physical and psychological safety of the patients and avoidance of any form of abuse against the patients, their family caregivers, and the surgical team were also accentuated. Based on the findings, personal and professional excellence can be achieved through conscious and voluntary actions by the personnel to correct their shortcomings, improvement of the capabilities of colleagues, and effective teamwork.

\section{CONCLUSION}

Despite various advances in technology, communication, and lifestyle, there are no major improvements in ethical behavior. More than ever before, abuse and unethical behavior are observed against patients, their family caregivers, and medical teams. Regretfully, it is always the nurses who eventually pay the ultimate price for such misbehaviors in the healthcare system. The findings of the present study on ethical behavior in the OR enlighten healthcare managers toward designing better policies and plans for patient care. As a direct result, the nursing profession will be respected more and ethical behavior and professionalism will become widespread.

\section{LIMITATIONS AND RECOMMENDATIONS}

Due to the inherent nature of qualitative studies, the main limitation of the present study was the participation of OR personnel from a single city, which limits the generalizability of our findings. It is recommended that further studies are performed using other study designs such as grounded theory. 


\section{ACKNOWLEDGEMENT}

The present manuscript was extracted from the Ph.D. thesis. The study was sponsored by Shiraz University of Medical Sciences, Shiraz, Iran (code: 95-01-08-14008). We would like to thank the participants for their time, effort, and contribution to the study.

\section{Conflict of Interest}

None declared.

\section{REFERENCES}

1. Hillgard E. The field of psychology of the Hillgard. Tehran: Roshd Publisher, 2014.

2. Rabbani R, Ramezani M. Investigating the Impact of the Environment on Individual and Social Behavior from the Viewpoint of Ibn Khaldun. Islamic Revolutionary Research 2006;10.

3. Mohseni M. Preparations for sociology. Tehran: Doran Publisher, 2011.

4. Butis J, Rich K. Nursing Ethics. Boston: Jones: Bartlett Publishers, 2008

5. Killen AR. Morality in perioperative nurses. AORN journal. 2002;75:532-49. https://doi.org/10.1016/S0001-2092(06) 61175-7

6. Narvaez D, Rest j. Morality A common concern counselling and human development. 1999.

7. Maroto-Sánchez A. Productivity in the services sector: conventional and current explanations. The Service Industries Journal. 2012;32:719-46. https://doi.org/ 10.1080/02642069.2010.531266

8. Savage JS, Favret JO. Nursing students' perceptions of ethical behavior in undergraduate nursing faculty. Nurse Education in Practice. 2006;6:47-54. https://doi.org/ 10.1016/j.nepr.2005.08.002 PMid:19040855

9. Borhani F, Abbaszadeh A, Kohan M, Fazael M. Comparssion of the Moral Resoning Ability of Nurses and Nursing Students at Kerman University of Medical Sciences in Dealing with Ethical Problems. J Med Ethic History Med. 2010;4:74-6.

10. Chinn PL, Kramer MK. Knowledge Development in NursingE-Book: Theory and Process. Elsevier Health Sciences, 2014.

11. Taylor C, Lillis C, LeMone P, Lynn PA. Fundamentals of nursing: The art and science of nursing care. Lippincott Philadelphia, 2001.

12. De Cremer D, Mayer DM, Schminke M. Guest editors' introduction: On understanding ethical behavior and decision making: A behavioral ethics approach. Business Ethics Quarterly. 2010;20:1-6. https://doi.org/10.1007/ s10551-011-0789-x

13. Cropanzano R, Stein JH. Organizational justice and behavioral ethics: Promises and prospects. Business Ethics Quarterly. 2009;19:193-233. https://doi.org/10.5840/ beq200919211

14. Gilmartin J, Wright K. Day surgery: patients' felt abandoned during the preoperative wait. Journal of Clinical Nursing. 2008;17:2418-25. https://doi.org/10.1111/j.1365-2702.2008 02374.x PMid:18705721
15. Abdollah Zadeh F, Lotfi M, Aqazadeh A, Asl Z. Viewpoints of operating room staff and students toward ethical climate in teaching hospitals of Tabriz University of Medical Sciences. Medical Ethics Journal. 2015;9.

16. Sanagoo A, Yazdani S, Jouybari L, Kalantari S. Uncivil behaviors in nurses work environment: a qualitative study. Iranian Journal of Psychiatric Nursing. 2017;4. https://doi.org/10.21859/ijpn-04067

17. Ahmadi M. Survey of workplace violence and related factors in the health personnel in operating room in the educational-medical centers of Esfahan university of Medical Sciences in 2017-18. Esfahan, Iran: Esfahan university of Medical Sciences, 2018.

18. Pivec M. Play and learn: potentials of game - based learning. British Journal of Educational Technology. 2007;38:387-93. https://doi.org/10.1111/j.1467-8535.2007. 00722.x

19. Ketefian S. A case study of theory development: Moral behavior in nursing. 1987. https://doi.org/10.1097/ 00012272-198701000-00005 PMid:3099633

20. Abbaszadeh A, Abedi H, Ghofrani F, Sharif FDaenepm. Designing and evaluating nurses' ethical performance model. Medicine and cultivation. 2002;47.

21. Raines ML. Ethical decision making in nurses. Relationships among moral reasoning, coping style, and ethics stress. JONA'S healthcare law, ethics and regulation. 2000;2:2941. https://doi.org/10.1097/00128488-200002010-00006

22. de Casterlé BD, Grypdonck M, Vuylsteke-Wauters M. Development, reliability, and validity testing of the Ethical Behavior Test: a measure for nurses' ethical behavior. Journal of nursing measurement. 1997;5:87-112. https://doi.org/10.1891/1061-3749.5.1.87

23. Bakaeen F, Awad S, Albo D, et al. Epidemiology of exposure to blood borne pathogens on a surgical service. The American Journal of Surgery. 2006;192:e18-e21. https://doi.org/10.1016/j.amjsurg.2006.08.013 PMid: 17071175

24. Chen C-K, Lin C, Wang S-H, Hou T-H. A study of job stress, stress coping strategies, and job satisfaction for nurses working in middle-level hospital operating rooms. Journal of Nursing Research. 2009;17:199-211. https://doi.org/ 10.1097/JNR.0b013e3181b2557b PMid:19738448

25. Asadi Fakhr A, Asadi S. Investigation of the amount of stressors in operating room nurses. Pajouhan Scientific Journal. 2017;15.

26. Khodaveisi M, Mohammadi N, Omidi A. Frequency of job stress in clinical nurses. Scientific Journal of Hamadan Nursing \& Midwifery Faculty. 2006;13.

27. Brasel KJ, Mol C, Kolker A, Weigelt JA. Needlesticks and surgical residents: who is most at risk? Journal of surgical education. 2007;64:395-8. https://doi.org/10.1016/ j.jsurg.2007.04.003 PMid:18063276

28. Rezaei Ronaghi J, Paravar M, Rezaei M, Ebrahimi H. Relationship between burnout and social support in emergency medical personnel in Kashan city. JKH. 2016;11:63-72.

29. Keyvanara M, Shaarbafchi Zadeh N, Alimoradnori M Occupational Burnout in the Operating Room Staff in Teaching Hospitals: Affiliated Isfahan University of Medical Sciences in 2016. Journal of Payavard Salamat. 2018;12. https://doi.org/10.18502/jebhpme.v3i3.1509 
30. Dimou FM, Eckelbarger D, Riall TS. Surgeon burnout: a systematic review. Journal of the American College of Surgeons. 2016;222:1230. https://doi.org/10.1016/j.jamcoll surg.2016.03.022 PMid:27106639 PMCid:PMC4884544

31. Shoorideh FA, Ashktorab T, Yaghmaei F, Majd HA. Religious responses of ICU nurses to moral distress: A qualitative study. Journal of Research on Religion \& Health. 2016;1:312.

32. Borhani F, Mohammadi S, Roshanzadeh M. Moral distress and perception of futile care in intensive care nurses. Journal of medical ethics and history of medicine. 2015;8.

33. Mohammadi S, Borhani F, Roshanzadeh M. Moral distress and relationship between Physician and nurses. Medical Ethics Journal. 2016;10. https://doi.org/10.21859/mej10367

34. Abbasi M, Hajatmand F, Khaghanizadeh M, Gashtroudkhani AA. Moral distress in nurses employed in selected hospitals of Shahid Beheshti University of Medical Sciences. Medical Ethics Journal. 2015;9:121-40.

35. Mardani Hamooleh M, Iranshahi M, Seyedfatemi N, Haghani $\mathrm{H}$. An evaluation of moral distress levels among the nursing staff of Malayer hospitals: A cross-sectional study. Iranian Journal of Medical Ethics and History of Medicine. 2016;9:42-53.

36. Narayanasamy A, Andrews A. Cultural impact of Islam on the future directions of nurse education. Nurse education today. 2000;20:57-64. https://doi.org/10.1054/nedt.2000. 0425 PMid:11138216

37. Sadeghi R, Ashktorab T. Ethical problems observed by nurse students: Qualification approach. Medical Ethics Journal. 2011;5:43-62.

38. Eshkevari KV, Karimi M, Asnaashari H, Kohan N. The assessment of observing patients' right in Tehran University of Medical Sciences' hospitals. Iran J Med Ethics Hist Med. 2009;2:47-54.

39. Dadkhah B, Mohammadi MA, Mozaffari N. Respect rate of patients rights in Ardabil Hospitals in 2002. 2010;9.

40. Ghavami H, Mohammadi E, Ahmadi F, Basirnia N. Patient's rights regarding the examination and control of pain after operation. Urmia Medical Journal. 2005;16.

41. Saber S, Kianian T, Mehrabian S, Bastami M. Observance of professional ethics in the performance of invasive procedures by nurses. Medical Ethics Journal. 2015;9:7593.

42. Nikkhah Farkhani Z, Rahimnia F, Kazemi M, Shirazi A. Modeling the ethical behavior of nurses using the theory of virtue ethics. Iranian Journal of Medical Ethics and History of Medicine. 2015;7:29-48.

43. Memarian R, Salsali M, Vaaki Z, Ahmadi F, Hajizade A. Effective factors in the process of achieving clinical competency. Scientific Journal of Zanjan University of Medical Sciences. 2007;14. https://doi.org/10.1177/ 0969733007073715 PMid:17425149

44. Jafaraghaee F, Mehrdad N, Parvizy S. Barriers and facilitators of nursing professional commitment: a qualitative study. Nursing Research. 2014;9.

45. Gould D, Fontenla M. Commitment to nursing: results of a qualitative interview study. Journal of Nursing Management. 2006;14:213-21. https://doi.org/10.1111/ j.1365-2934.2006.00577.x PMid:16600010
46. McCabe TJ, Garavan TN. A study of the drivers of commitment amongst nurses: The salience of training, development and career issues. Journal of European Industrial Training. 2008;32:528-68. https://doi.org/ 10.1108/03090590810899829

47. LLapa-Rodríguez EO, Trevizan MA, Shinyashiki GT Conceptual reflections about organizational and professional commitment in the health sector. Revista latino-americana de enfermagem. 2008;16:484-8. https://doi.org/10.1590/S0104-11692008000300024 PMid: 18695826

48. Wolf ZR, Hoerst B. Professional commitment in RN-BSN and basic BSN students: program evaluation. Nurse educator. 2007;32:61-5. https://doi.org/10.1097/01.NNE.0000264329. 63662.1b PMid:17496820

49. Tehranineshat B, Rakhshan M, Torabizadeh C, Fararouei M. Nurses', patients', and family caregivers' perceptions of compassionate nursing care. Nursing ethics. 2018:0969733018777884. https://doi.org/10.1177/096973 3018777884 PMid:29898620

50. Bahreini M, Ahmadi F, Shahamat S, Behzadi S. Effect of professional port folio in clinical nurses competence. Journal of development and studies center in medical education. 2011;8.

51. Badger K, Royse D. Describing compassionate care: The burn survivor's perspective. Journal of Burn Care \& Research. 2012;33:772-80. https://doi.org/10.1097/BCR. 0b013e318254d30b PMid:22929523

52. Teng C-I, Shyu Y-IL, Chang H-Y. Moderating effects of professional commitment on hospital nurses in Taiwan. Journal of Professional Nursing. 2007;23:47-54. https://doi.org/10.1016/j.profnurs.2006.10.002 PMid:17292133

53. Shaker M. Ethics and Human Being/A comment in the Book of morality in Molana View. Tehran: Moon religion, 2009.

54. Farabi A. Thoughts of the utopian Medina. Tehran: Ministry of Culture and Islamic Guidance/Printing and Publishing Organization, 2000.

55. Ravari A, Marzaei T, Kazamnezhad A. Spiritual approach to clinical nurses' job satisfaction: a qualitative study. Payesh Journal. 2016;10.

56. Courtney M, Farnworth L. Professional competence for private practitioners in occupational therapy. Australian Occupational Therapy Journal. 2003;50:234-43. https://doi.org/10.1111/j.1440-1630.2003.00402.x

57. Organ DW. Organizational citizenship behavior: The good soldier syndrome. Lexington Books/DC Heath and Com, 1988.

58. Rezapour Nasrabad R. Leadership Skills Is Necessary For Extray Roles Behaviors And Professional Excellence. 2016. https://doi.org/10.29252/ijnv.5.1.9

59. Parsapoor A, Bagheri A, Larijani B. Patient's rights charter in Iran. Acta Medica Iranica. 2014:24-8.

60. O'Leary KJ, Buck R, Fligiel HM, et al. Structured interdisciplinary rounds in a medical teaching unit: improving patient safety. Archives of Internal Medicine. 2011;171:678-84. https://doi.org/10.1001/archinternmed. 2011.128 PMid:21482844

61. Baker VOT, Cuzzola R, Knox C, et al. Teamwork education improves trauma team performance in undergraduate health professional students. Journal of educational evaluation for health professions. 2015;12. https://doi.org/10.3352/jeehp.2015.12.36 PMid:26101404 PMCid:PMC4536358 
62. Borji M, Nourmohammadi H, Otaghi M, Salimi AH, Tarjoman A. Positive effects of cognitive behavioral therapy on depression, anxiety and stress of family caregivers of patients with prostate cancer: A randomized clinical trial. Asian Pacific journal of cancer prevention: APJCP. 2017;18:3207.

63. Gastmans C. Dignity-enhancing nursing care: a foundational ethical framework. Nursing Ethics. 2013;20:142-9. https://doi.org/10.1177/0969733012473772 PMid:23466947

64. Lin YP, Tsai YF. Maintaining patients' dignity during clinical care: a qualitative interview study. Journal of advanced nursing. 2011;67:340-8. https://doi.org/10.1111/j.13652648.2010.05498.x PMid:21044135

65. G. R. Theory of Sociology in the Contemporary World. Publishers scientific, 1998.

66. Almoajel AM. Hospitalized patients' awareness of their rights in Saudi governmental hospital. Middle-East Journal of Scientific Research. 2012;11:329-35.

67. Ross D, Vasantha S. Study on the Level of Hospital Staffs' Awareness on Patients' Rights. Int J Adv Res. 2014;2:770-6.

68. Heidari A, Ahmadpour Z, GharehBoughlou Z. Patients and nurses awareness of patient's rights: A comparative study. Health, Spirituality and Medical Ethics. 2013;1.

69. Phillips N. Berry and Kohen's Operating Room Techniques. St Louis: Mosby, 2013.

70. 2011. SPAfhwpiipoccvailc. Patients' bill of rights.

71. Zandiyeh M, Pakro Payravandi A, Imani B, Ahmadi S, Roshanaei G. Quality of compliance of patient's rights in operating rooms of Hamadan's educational hospitals in 2012. Pajouhan Scientific Journal. 2015;13.

72. Parsapoor A, Mohammad K, Afzali HM, Ala'eddini F, Larijani B. Necessity of observing patient's rights: a survey on the attitudes of patients, nurses and physicians. Journal of medical ethics and history of medicine. 2012;5.

73. Reed PG, Shearer NBC. Perspectives on nursing theory. Lippincott Williams \& Wilkins, 2009.

74. Alligood MR. Nursing Theorists and Their Work-E-Book. Elsevier Health Sciences, 2017.

75. Bailey L. Strategies for decreasing patient anxiety in the perioperative setting. AORN journal. 2010;92:445-60. https://doi.org/10.1016/j.aorn.2010.04.017 PMid:20888947

76. Moosavi S. Professional Problems of Operating Rooms from the Standpoint of Personnel in Iran Between 2001-2002. ournal of Guilan University of Medical Sciences. 2003;12.
77. Lin YP, Tsai YF, Chen HF. Dignity in care in the hospital setting from patients' perspectives in Taiwan: a descriptive qualitative study. Journal of clinical nursing. 2011;20:794801. https://doi.org/10.1111/j.1365-2702.2010.03499.x PMid:21320204

78. Sonoda Y, Onozuka D, Hagihara A. Factors related to teamwork performance and stress of operating room nurses. Journal of nursing management. 2018;26:66-73. https://doi.org/10.1111/jonm.12522 PMid:28744975

79. Nguyen N, Watson WD, Dominguez E. An event-based approach to design a teamwork training scenario and assessment tool in surgery. Journal of surgical education. 2016;73:197-207. https://doi.org/10.1016/j.jsurg.2015.10. 005 PMid:26774937

80. Albina JK. Patient abuse in the health care setting: The nurse as patient advocate. AORN journal. 2016;103:73-81. https://doi.org/10.1016/j.aorn.2015.10.021 PMid:26746029

81. Fazel E, Abbassioun K, Sehhat S, et al. Operating Room The Base Of Morality And The Basis Of Humanistic Professional Duties. Iranian Journal of Surgery. 2017;25.

82. Organization WH. World alliance for patient safety: WHO draft guidelines for adverse event reporting and learning systems: from information to action. Geneva: World Health Organization, 2005.

83. Gazerani A, Aliakbari R, Habibzadeh M, Haresabadi M. Assessment of Safety Status in operating room by the World Health Organization Standards for Safety-Friendly Hospital. Journal of North Khorasan University of Medical Sciences. 2014;6. https://doi.org/10.29252/jnkums.6.4.895

84. Hall P. Interprofessional teamwork: Professional cultures as barriers. Journal of Interprofessional care. 2005;19:18896. https://doi.org/10.1080/13561820500081745 PMid:16096155

85. Ajalli A, Fallahi Khoshknab M, Hosseini MA, Mohammadi I, Sirati Nir M. Exploring the Nurses' Perception of Patient Safety in Psychiatric Wards: A Qualitative Study. Iranian Journal of Psychiatric Nursing. 2017;5:52-60. https://doi.org/10.21859/ijpn-05047

86. Deering S, Rosen MA, Ludi V, et al. On the front lines of patient safety: implementation and evaluation of team training in Iraq. The Joint Commission Journal on Quality and Patient Safety. 2011;37:350-AP1. https://doi.org/ 10.1016/S1553-7250(11)37045-6 